\title{
Nitrosoarene Dimerization on Two- and Three-dimensional Gold Surfaces
}

\author{
Ivana Biljan, ${ }^{\text {a,* }}$ Tina Medančić, ${ }^{a}$ Marko Kralj, ${ }^{\text {b }}$ Tea Mišić Radić, \\ Vesna Svetličić, ${ }^{\mathrm{j}}$ and Hrvoj Vančik, ${ }^{\mathrm{a}, *}$ \\ ${ }^{a}$ Department of Chemistry, Faculty of Science, University of Zagreb, Horvatovac 102A, HR-10000 Zagreb, Croatia \\ ${ }^{\mathrm{b}}$ Institute of Physics, Bijenicka 46, HR-10000 Zagreb, Croatia \\ ${ }^{\mathrm{c}}$ Ruđer Bošković Institute, Bijenička 54, HR-10000 Zagreb, Croatia
}

RECEIVED NOVEMBER 23, 2011; REVISED JANUARY 23, 2013; ACCEPTED JANUARY 23, 2013

\begin{abstract}
In the present study, we investigated nitrosoarene dimerization on an $\mathrm{Au}(111)$ and on the surface of gold nanoparticles (AuNPs). High-resolution STM images revealed that 8-thiocyanatooctyl-4nitrosobenzoate $\left(\mathrm{NCS}\left(\mathrm{CH}_{2}\right)_{8} \mathrm{OOCC}{ }_{6} \mathrm{H}_{4} \mathrm{NO}\right)$ forms well-ordered monolayer on an $\mathrm{Au}(111)$ surface displaying hexagonal $3 \sqrt{3} \times 3 \sqrt{3}$ structure. AFM data indicated that this compound also dimerize on an $\mathrm{Au}(111)$ surface thus forming bilayers. On contrary, adsorption of 6-(4-nitrosophenoxy)hexane-1-thiol $\left(\mathrm{HS}\left(\mathrm{CH}_{2}\right)_{6} \mathrm{OC}_{6} \mathrm{H}_{4} \mathrm{NO}\right)$ on an $\mathrm{Au}(111)$ leads only to poorly organized monolayer.

Furthermore, it was found that nitrosoarene derivatives 8-thiocyanatooctyl-4-nitrosobenzoate $\left(\mathrm{NCS}\left(\mathrm{CH}_{2}\right)_{8} \mathrm{OOCC}_{6} \mathrm{H}_{4} \mathrm{NO}\right)$ and 3-thiocyanatopropyl-4-nitrosobenzoate $\left(\mathrm{NCS}\left(\mathrm{CH}_{2}\right)_{3} \mathrm{OOCC}_{6} \mathrm{H}_{4} \mathrm{NO}\right)$ are present as dimers on the surface of AuNPs. There is no appreciable quantity of dimeric species with free thiocyanate termini indicating interlinkage of AuNPs through azodioxide bonds. Besides the characteristic surface plasmon band, UV-vis spectra showed an additional red-shifted band that might have origin in aggregation of AuNPs. This was further supported by TEM revealing the appearence of larger aggregates in addition to smaller AuNPs.(doi: 10.5562/cca2023)
\end{abstract}

Keywords: C-nitrosoarenes, azodioxides, self-assembled monolayers, self-assembled bilayers, gold nanoparticles

\section{INTRODUCTION}

There are numerous reports in the literature on the tendency of C-nitrosoarenes to dimerize to azodioxides. ${ }^{1-11}$ While predominant species in solution at ambient temperature are monomers, lowering of temperature or crystallization favors formation of dimers. ${ }^{12,13}$ Besides, dimerization is also possible in polymers. ${ }^{14}$ Apart that dimerization in solid state depends on electronic factors, previous studies have revealed that this process is also strongly affected by the molecular arrangement in the crystal lattice (topochemical effects). Thus if molecules are favorably oriented with their nitroso groups in the vicinity, formation of azodioxides in crystals is strongly preferred. ${ }^{15}$ Under cryogenic conditions in crystals, azodioxides undergo photodissociation to monomers, and in turn, by warming above some critical temperature redimerization occurs. ${ }^{16}$ Therefore, this system represents a sort of molecular OFF-ON switch. Since the strength of the azodioxide $(\mathrm{O}) \mathrm{N}=\mathrm{N}(\mathrm{O})$ bond is comparable with the average hydrogen bond, ${ }^{17}$ the property of nitrosoarenes to dimerize could be used to build novel supramolecular architectures with special properties of intelligent materials.

In our recent work we have suggested that dimerization of nitrosoarenes is also possible at the metalsolution interface through formation of ordered selfassembled bilayers (SABs) on an $\mathrm{Au}(111)$ surface. $^{18}$ SABs can be formed by vertical interactions of nitroso-groups exposed at the interface of self-assembled monolayer (SAM) and those present in solution via $(\mathrm{O}) \mathrm{N}=\mathrm{N}(\mathrm{O})$ bonds. Here we extend our knowledge on the nitrosoarene dimerization at the metal-solution interface by investigating how it is affected by structural factors e.g. strong electron-donating substituents and various alkyl chain lengths. Moreover, we were interested whether nitrosoarene dimerization also occurs on the 3D surface of gold nanoparticles (AuNPs) subsequently leading to aggregation of AuNPs via $(\mathrm{O}) \mathrm{N}=\mathrm{N}(\mathrm{O})$ bonds. Besides gaining valuable new insights into the dimerization properties of Cnitrosoarenes, these supramolecular systems provide potential for novel applications. Due to the photo-

\footnotetext{
* Authors to whom correspondence should be addressed. (E-mails: vancik@chem.pmf.hr, ibiljan@chem.pmf.hr)
} 
chromic and thermochromic behavior of Cnitrosoarenes in solid state, ${ }^{16}$ layers on an $\mathrm{Au}(111)$ surface and AuNPs aggregates formed via azodioxide bonds could eventually be triggered by light or heat. In addition, the presence of sulphur groups at outer surface of the SABs formed on an $\mathrm{Au}(111)$ may provide a simple means for the fabrication of metallic layers with applications in molecular electronics. ${ }^{19-23}$ Additionally, the system of AuNPs interlinked through $(\mathrm{O}) \mathrm{N}=\mathrm{N}(\mathrm{O})$ bonds could be easily manipulated by introducing various functional end-groups, e.g. nitro or azoxy, thus affecting interconnection of AuNPs. For example, if one wishes to link nanoparticles permanently and prevent dissociation of the azodioxide group, it can be reduced to the azoxy $((\mathrm{O}) \mathrm{N}=\mathrm{N})$ group. On the other hand, if one wishes to prevent interlinking of nanoparticles, the nitroso terminus can be easily oxidized to nitro group.

In order to further investigate dimerization of $\mathrm{C}$ nitrosoarenes on an $\mathrm{Au}(111)$ surface we have prepared two novel nitrosoarene derivatives (compounds $\mathbf{1}$ and 2, Scheme 1). In contrast to compound $\mathbf{2}$ and nitrosoarene derivatives studied previously ${ }^{18}$ that are all dimers, compound $\mathbf{1}$ appears as monomer. Dimerization of $\mathbf{1}$ is prohibited due to the negative charge on the NO-group ${ }^{24}$ what can be explained by the contribution of quinoid resonance structure (depicted as structure II in Scheme 2). ${ }^{25,26}$

In addition, to explore the possibility of aggregation of AuNPs via azodioxide $(\mathrm{O}) \mathrm{N}=\mathrm{N}(\mathrm{O})$ bonds we have prepared AuNPs capped by
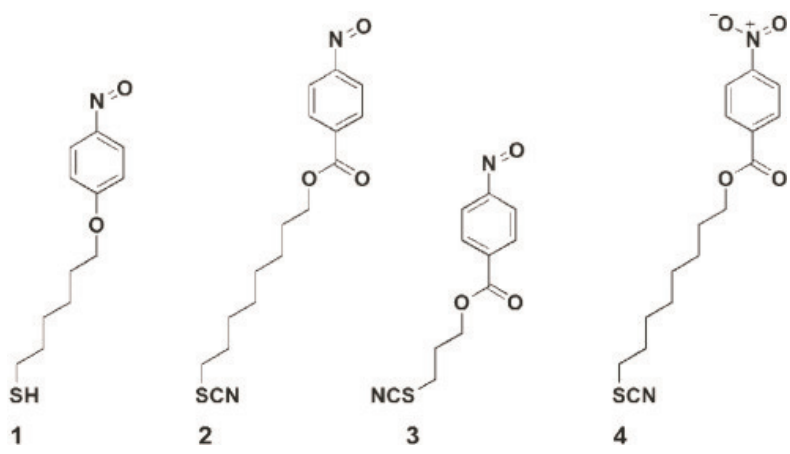

Scheme 1.

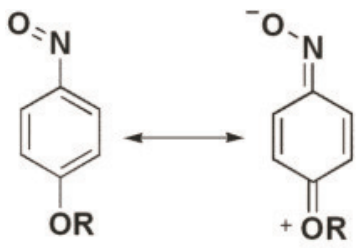

(I)

(II) nitrosoarene derivatives $\mathbf{2}$ and $\mathbf{3}$ (Scheme 1). The effect of interlinking was further tested on an analogous system with nitroarene alkyl thiocyanate (compound $\mathbf{4}$, Scheme 1) where interlinking of AuNPs is prevented by introducing nitro functionality. Compounds 1-4 were functionalized with thiol (compound 1) or thiocyanate headgroups (compounds 2, 3 and 4) for adsorption on the gold (2D or 3D) surface. Besides the advantage of being more stable in comparison to thiols, the usage of thiocyanates for adsorption on the AuNPs enabled us to easily follow whether the molecule is bound to gold or not just by looking at disappearance of the relatively strong SCN signal in FTIR spectrum. As noted previously, thiocyanates adsorb on the gold surface by forming thiolate ( $\mathrm{RS}-\mathrm{Au}$ ) bond analogous to free thiols. ${ }^{27,28}$

Adlayers formed on an $\mathrm{Au}(111)$ surface where characterized by scanning tunneling microscopy (STM) and atomic force microscopy (AFM), while for characterization of AuNPs FTIR spectroscopy, UV-vis spectroscopy and transmission electron microscopy (TEM) were used.

\section{EXPERIMENTAL}

\section{General Information}

All chemicals were used as received from supplier. The solvents were purified or dried according to literature procedures. Reactions were carried out under an inert atmosphere of nitrogen or argon. The course of the reactions was monitored by TLC (Merck silica gel 60$\mathrm{F}_{254}$-coated plates). Column chromatography was performed with silica gel 60 (Fluka, $0.063-0.200 \mathrm{~mm}$ ). ${ }^{1} \mathrm{H}$ and ${ }^{13} \mathrm{C}$ NMR spectra were recorded on a Bruker AV600 spectrometer. The chemical shifts ( $\delta)$ are reported as ppm relative to TMS. FTIR spectra were recorded on a Bruker Equinox FTIR spectrometer under $4 \mathrm{~cm}^{-1}$ resolution.

Nitrosoarene derivatives were prepared from corresponding nitroarenes by standard procedures based on $\mathrm{Zn}$ reduction followed by oxidation with $\mathrm{FeCl}_{3}{ }^{29,30}$ Bunte salt $\mathbf{1 b}$ and thiol 1c were prepared by adaptation of literature procedure described previously. ${ }^{31}$ Compounds $\mathbf{2}$ and $\mathbf{4}$ were prepared following the procedure described in our recent paper for compound 3. ${ }^{18}$ Compounds $\mathbf{2}$ and $\mathbf{3}$ were isolated as dimers after purification.

\section{Synthesis}

6-(4-nitrophenoxy)hexane-1-bromide (1a). The mixture of 4-nitrophenole (0.02 mmol), 1,6dibromohexane $(0.15 \mathrm{~mol})$, potassium carbonate $(0.11$ mol) and catalytic amount of potassium iodide in acetone $\left(100 \mathrm{~cm}^{3}\right)$ was refluxed for $20 \mathrm{~h}$. After cooling to 
room temperature the reaction mixture was filtered and the solvent was evaporated. The residue was purified by column chromatography (silica gel, starting with petroleter/DCM $=3 / 1$ increasing to DCM). 1a was obtained as yellow oil which solidifies upon staying in refrigerator with a yield of $71 \% . \delta_{\mathrm{H}}\left(600 \mathrm{MHz} ; \mathrm{CDCl}_{3}\right.$; $\left.\mathrm{Me}_{4} \mathrm{Si}\right): 1.5\left(4 \mathrm{H}, \mathrm{m}, \mathrm{CH}_{2} \mathrm{CH}_{2}\right), 1.8\left(4 \mathrm{H}, \mathrm{m}, \mathrm{CH}_{2} \mathrm{CH}_{2}\right)$, $3.4\left(2 \mathrm{H}, \mathrm{t}, \mathrm{CH}_{2}-\mathrm{Br}\right), 4.1\left(2 \mathrm{H}, \mathrm{t}, \mathrm{CH}_{2}-\mathrm{O}\right), 7.0(2 \mathrm{H}, \mathrm{m}$, $\mathrm{Ph}), 8.2(2 \mathrm{H}, \mathrm{m}, \mathrm{Ph}) . \delta_{\mathrm{C}}\left(150.90 \mathrm{MHz} ; \mathrm{CDCl}_{3} ; \mathrm{Me}_{4} \mathrm{Si}\right)$ : $25.2\left(\mathrm{CH}_{2}\right), 27.8\left(\mathrm{CH}_{2}\right), 28.8\left(\mathrm{CH}_{2}\right), 32.6\left(\mathrm{CH}_{2}\right), 33.7$ $\left(\mathrm{CH}_{2}-\mathrm{Br}\right), 68.6\left(\mathrm{CH}_{2}-\mathrm{O}\right), 114.4(\mathrm{Ph}), 125.9(\mathrm{Ph})$, $141.4\left(\mathrm{C}-\mathrm{NO}_{2}\right), 164.1(\mathrm{C}-\mathrm{O}) . \mathrm{IR}(\mathrm{NaCl}) v_{\max } / \mathrm{cm}^{-1}$ : $1514\left(\mathrm{NO}_{2}\right.$ asymmetric), $1341\left(\mathrm{NO}_{2}\right.$ symmetric $), 1261$ (C-O).

Bunte salt $(\mathbf{1 b})$. To a solution of $1 \mathbf{a}(3.31 \mathrm{mmol})$ in ethanol $\left(12 \mathrm{~cm}^{3}\right)$ solution of sodium thiosulfate pentahydrate $(3.5 \mathrm{mmol})$ in water $\left(3.5 \mathrm{~cm}^{3}\right)$ was added. The mixture was refluxed for $3 \mathrm{~h}$. After cooling reaction mixture to room temperature, solvent was evaporated to approximately $2 \mathrm{~cm}^{3}$. Upon refrigeration $1 \mathbf{b}$ precipitated with a yield of $86 \%$.

6-(4-nitrophenoxy)hexane-1-thiol (1c). 1b was added $(2.8 \mathrm{mmol})$ to a mixture of chloroform $\left(20 \mathrm{~cm}^{3}\right)$ and hydrochloride acid $\left(1 \mathrm{~mol} \mathrm{dm}{ }^{-3}, 20 \mathrm{~cm}^{3}\right)$. The mixture was refluxed for $2 \mathrm{~h}$. After cooling to room temperature organic phase was separated while an aqueous phase was extracted two times with chloroform $\left(20 \mathrm{~cm}^{3}\right)$. After drying combined organic extracts over $\mathrm{Na}_{2} \mathrm{SO}_{4}$, solvent was evaporated. 1c was obtained as a yellow oil with a yield of $75 \% . \delta_{\mathrm{H}}\left(600 \mathrm{MHz} ; \mathrm{CDCl}_{3} ; \mathrm{Me}_{4} \mathrm{Si}\right): 1.3$ $(1 \mathrm{H}, \mathrm{t}, \mathrm{SH}), 1.5\left(4 \mathrm{H}, \mathrm{m}, \mathrm{CH}_{2} \mathrm{CH}_{2}\right), 1.7\left(2 \mathrm{H}, \mathrm{m}, \mathrm{CH}_{2}\right), 1.8$ $\left(2 \mathrm{H}, \mathrm{m}, \mathrm{CH}_{2}\right), 2.6\left(2 \mathrm{H}, \mathrm{q}, \mathrm{CH}_{2}-\mathrm{SH}\right), 4.1(2 \mathrm{H}, \mathrm{t}$, $\left.\mathrm{CH}_{2}-\mathrm{O}\right), 7.0(2 \mathrm{H}, \mathrm{m}, \mathrm{Ph}), 8.2(2 \mathrm{H}, \mathrm{m}, \mathrm{Ph}) . \delta_{\mathrm{C}}(150.90$ $\left.\mathrm{MHz} ; \mathrm{CDCl}_{3} ; \mathrm{Me}_{4} \mathrm{Si}\right): 23.9\left(\mathrm{CH}_{2}\right), 24.9\left(\mathrm{CH}_{2}\right), 27.5$ $\left(\mathrm{CH}_{2}\right), 28.3\left(\mathrm{CH}_{2}\right), 33.3\left(\mathrm{CH}_{2}-\mathrm{SH}\right), 68.2\left(\mathrm{CH}_{2}-\mathrm{O}\right)$, $113.9(\mathrm{Ph}), 125.4(\mathrm{Ph}), 140.9\left(\mathrm{C}-\mathrm{NO}_{2}\right), 163.7(\mathrm{C}-\mathrm{O})$. IR (NaCl) $v_{\max } / \mathrm{cm}^{-1}: 2580(\mathrm{~S}-\mathrm{H}), 1507\left(\mathrm{NO}_{2}\right.$ asymmetric), $1340\left(\mathrm{NO}_{2}\right.$ symmetric $), 1260(\mathrm{C}-\mathrm{O})$.

6-(4-nitrosophenoxy)hexane-1-thiol (1). To an ice-cold solution of $1 \mathrm{c}(1.75 \mathrm{mmol})$ in acetone $\left(5 \mathrm{~cm}^{3}\right)$, ammonium chloride $(2.62 \mathrm{mmol})$ and finely powdered zinc $(5.35 \mathrm{mmol})$ were added. After that, water $\left(5 \mathrm{~cm}^{3}\right)$ was slowly added while stirring. Reaction mixture was further stirred for $30 \mathrm{~min}$ and then poured over $20 \mathrm{~cm}^{3}$ of ice. The mixture was filtered and washed with acetone. Solution of $\mathrm{FeCl}_{3}(1.23 \mathrm{mmol})$ in $\mathrm{H}_{2} \mathrm{O}\left(\mathrm{c} \mathrm{cm}^{3}\right)$ was added to the filtrate. Obtained green-colored mixture was extracted three times with $\mathrm{CH}_{2} \mathrm{Cl}_{2}\left(10 \mathrm{~cm}^{3}\right)$ and the collected organic extracts were dried over $\mathrm{Na}_{2} \mathrm{SO}_{4}$. After evaporation of the solvent the crude product was purified by column chromatography eluting with DCM to afford a product as a green oil (nitroso monomer) with a yield of $31 \% . \delta_{\mathrm{H}}(600 \mathrm{MHz}$; $\left.\mathrm{CDCl}_{3} ; \mathrm{Me}_{4} \mathrm{Si}\right): 1.4(1 \mathrm{H}, \mathrm{t}, \mathrm{SH}), 1.5\left(4 \mathrm{H}, \mathrm{m}, \mathrm{CH}_{2} \mathrm{CH}_{2}\right)$, $1.7\left(2 \mathrm{H}, \mathrm{m}, \mathrm{CH}_{2}\right), 1.8\left(2 \mathrm{H}, \mathrm{m}, \mathrm{CH}_{2}\right), 2.7(2 \mathrm{H}, \mathrm{q}$,
$\left.\mathrm{CH}_{2}-\mathrm{SH}\right), 4.1\left(2 \mathrm{H}, \mathrm{t}, \mathrm{CH}_{2}-\mathrm{O}\right), 7.0(2 \mathrm{H}, \mathrm{m}, \mathrm{Ph}), 7.9$ $(2 \mathrm{H}, \mathrm{m}, \mathrm{Ph}) . \delta_{\mathrm{C}}\left(150.90 \mathrm{MHz} ; \mathrm{CDCl}_{3} ; \mathrm{Me}_{4} \mathrm{Si}\right): 25.1$ $\left(\mathrm{CH}_{2}\right), 27.6\left(\mathrm{CH}_{2}\right), 28.4\left(\mathrm{CH}_{2}\right), 28.5\left(\mathrm{CH}_{2}\right), 38.3$ $\left(\mathrm{CH}_{2}-\mathrm{SH}\right), 68.2\left(\mathrm{CH}_{2}-\mathrm{O}\right), 113.8(\mathrm{Ph}), 124.6(\mathrm{Ph})$, $163.5(\mathrm{C}-\mathrm{O}), 164.7(\mathrm{C}-\mathrm{NO}) . \quad$ IR $(\mathrm{NaCl}) v_{\max } / \mathrm{cm}^{-1}$ : $2586(\mathrm{~S}-\mathrm{H}), 1412(\mathrm{~N}=\mathrm{O}), 1262(\mathrm{C}-\mathrm{O}) . \quad$ Elemental analysis: Found: C, 60.42; H, 7.01; N, 5.65; O, 13.47; $\mathrm{S}, 13.45$. Calculated for $\mathrm{C}_{12} \mathrm{H}_{17} \mathrm{NO}_{2} \mathrm{~S}: \mathrm{C}, 60.22 ; \mathrm{H}$, 7.16; N, 5.85; O, 13.37; S, 13.40.

8-thiocyanatooctyl-4-nitrosobenzoate (2). Yield was 24 $\%$. $\delta_{\mathrm{H}}\left(600 \mathrm{MHz} ; \mathrm{CDCl}_{3} ; \mathrm{Me}_{4} \mathrm{Si}\right.$; nitroso monomer $): 1.3$ $\left(4 \mathrm{H}, \mathrm{m}, \mathrm{CH}_{2} \mathrm{CH}_{2}\right), 1.4\left(4 \mathrm{H}, \mathrm{m}, \mathrm{CH}_{2} \mathrm{CH}_{2}\right), 1.8(4 \mathrm{H}, \mathrm{m}$, $\left.\mathrm{CH}_{2} \mathrm{CH}_{2}\right), 2.9\left(2 \mathrm{H}, \mathrm{t}, \mathrm{CH}_{2}-\mathrm{SCN}\right), 4.3\left(2 \mathrm{H}, \mathrm{t}, \mathrm{CH}_{2}-\mathrm{O}\right)$, $7.9(2 \mathrm{H}, \mathrm{m}, \mathrm{Ph}), 8.2(2 \mathrm{H}, \mathrm{m}, \mathrm{Ph}) . \delta_{\mathrm{C}}(150.90 \mathrm{MHz}$; $\mathrm{CDCl}_{3} ; \mathrm{Me}_{4} \mathrm{Si}$; nitroso monomer): $25.4\left(\mathrm{CH}_{2}\right), 27.4$ $\left(\mathrm{CH}_{2}\right), 28.1\left(\mathrm{CH}_{2}\right), 28.3\left(\mathrm{CH}_{2}\right), 28.5\left(\mathrm{CH}_{2}\right), 29.3\left(\mathrm{CH}_{2}\right)$, $33.5\left(\mathrm{CH}_{2}-\mathrm{SCN}\right), 65.2\left(\mathrm{CH}_{2}-\mathrm{O}\right), 120.0(\mathrm{Ph}), 130.6$ $(\mathrm{Ph}), 164.0(\mathrm{C}-\mathrm{NO}), 164.7(\mathrm{C}=\mathrm{O})$. IR $(\mathrm{KBr}$; nitroso dimer) $v_{\max } / \mathrm{cm}^{-1}: 2152(\mathrm{SCN}), 1719(\mathrm{C}=\mathrm{O}), 1260$ $(\mathrm{ON}=\mathrm{NO})$. Elemental analysis: Found: $\mathrm{C}, 59.69 ; \mathrm{H}, 5.96$ $\mathrm{N}, \quad 8.82 ; \mathrm{O}, 15.23 ; \mathrm{S}, \quad 10.30$. Calculated for $\mathrm{C}_{16} \mathrm{H}_{20} \mathrm{~N}_{2} \mathrm{O}_{3} \mathrm{~S}: \mathrm{C}, 59.98 ; \mathrm{H}, 6.29 ; \mathrm{N}, 8.74 ; \mathrm{O}, 14.98 ; \mathrm{S}$, 10.00 .

3-thiocyanatopropyl-4-nitrosobenzoate (3). Yield was $23 \%$. $\delta_{\mathrm{H}}\left(600 \mathrm{MHz} ; \mathrm{CDCl}_{3} ; \mathrm{Me}_{4} \mathrm{Si}\right.$; nitroso monomer): $2.4\left(2 \mathrm{H}, \mathrm{m}, \mathrm{CH}_{2}\right), 3.1\left(2 \mathrm{H}, \mathrm{t}, \mathrm{CH}_{2}-\mathrm{SCN}\right), 4.5(2 \mathrm{H}, \mathrm{t}$, $\left.\mathrm{CH}_{2}-\mathrm{O}\right), 7.9(2 \mathrm{H}, \mathrm{m}, \mathrm{Ph}), 8.3(2 \mathrm{H}, \mathrm{m}, \mathrm{Ph}) . \delta_{\mathrm{C}}(150.90$ $\mathrm{MHz} ; \mathrm{CDCl}_{3} ; \mathrm{Me}_{4} \mathrm{Si}$; nitroso monomer): $29.2\left(\mathrm{CH}_{2}\right)$, $30.8\left(\mathrm{CH}_{2}-\mathrm{SCN}\right), 63.1\left(\mathrm{CH}_{2}-\mathrm{O}\right), 123.7(\mathrm{Ph}), 130.5$ $(\mathrm{Ph}), 165.5(\mathrm{C}=\mathrm{O})$. IR ( $\mathrm{KBr}$; nitroso dimer) $v_{\max } / \mathrm{cm}^{-1}$ : $2153 \quad(\mathrm{SCN}), \quad 1725 \quad(\mathrm{C}=\mathrm{O}), 1278 \quad(\mathrm{C}-\mathrm{O}), 1264$ $(\mathrm{ON}=\mathrm{NO})$. Elemental analysis: Found: $\mathrm{C}, 53.03 ; \mathrm{H}$, 3.93; N, 11.04; O, 19.39; S, 12.61. Calculated for $\mathrm{C}_{11} \mathrm{H}_{10} \mathrm{~N}_{2} \mathrm{O}_{3} \mathrm{~S}: \mathrm{C}, 52.79 ; \mathrm{H}, 4.03 ; \mathrm{N}, 11.19 ; \mathrm{O}, 19.18 ; \mathrm{S}$, 12.81 .

8-thiocyanatooctyl-4-nitrobenzoate (4). Yield was 78 \%. $\delta_{\mathrm{H}}\left(600 \mathrm{MHz} ; \mathrm{CDCl}_{3} ; \mathrm{Me}_{4} \mathrm{Si}\right): 1.5(8 \mathrm{H}, \quad \mathrm{m}$, $\left.\mathrm{CH}_{2} \mathrm{CH}_{2} \mathrm{CH}_{2} \mathrm{CH}_{2}\right), 1.8\left(4 \mathrm{H}, \mathrm{m}, \mathrm{CH}_{2} \mathrm{CH}_{2}\right), 2.9(2 \mathrm{H}, \mathrm{t}$, $\left.\mathrm{CH}_{2}-\mathrm{SCN}\right), 4.4\left(2 \mathrm{H}, \mathrm{t}, \mathrm{CH}_{2}-\mathrm{O}\right), 8.2(2 \mathrm{H}, \mathrm{m}, \mathrm{Ph}), 8.3$ $(2 \mathrm{H}, \mathrm{m}, \mathrm{Ph}) . \delta_{\mathrm{C}}\left(150.90 \mathrm{MHz} ; \mathrm{CDCl}_{3} ; \mathrm{Me}_{4} \mathrm{Si}\right): 25.9$ $\left(\mathrm{CH}_{2}\right), 27.8\left(\mathrm{CH}_{2}\right), 28.6\left(\mathrm{CH}_{2}\right), 28.8\left(\mathrm{CH}_{2}\right), 29.0$ $\left(\mathrm{CH}_{2}\right), 29.8\left(\mathrm{CH}_{2}\right), 34\left(\mathrm{CH}_{2}-\mathrm{SCN}\right), 66.0\left(\mathrm{CH}_{2}-\mathrm{O}\right)$, $123.5(\mathrm{Ph}), 130.7(\mathrm{Ph}), 135.8(\mathrm{C}-\mathrm{C}=\mathrm{O}), 164.7(\mathrm{C}=\mathrm{O})$. IR $(\mathrm{NaCl}) v_{\max } / \mathrm{cm}^{-1}: 2153(\mathrm{SCN}), 1721(\mathrm{C}=\mathrm{O}), 1526$ $\left(\mathrm{NO}_{2}\right.$ asymmetric $), 1348 \quad\left(\mathrm{NO}_{2}\right.$ symmetric $), 1274$ $(\mathrm{C}-\mathrm{O})$.

AuNPs capped by 2, 3 and 4. AuNPs were prepared by ligand exchange reactions from AuNPs protected by TOAB in order to avoid direct contact and possible reduction of the nitroso group by $\mathrm{NaBH}_{4} \cdot{ }^{32-34} \mathrm{~A} 30.0$ mmol dm${ }^{-3}$ aqueous solution of $\mathrm{HAuCl}_{4}\left(2.5 \mathrm{~cm}^{3}\right)$ and a $50.0 \mathrm{mmol} \mathrm{dm}{ }^{-3}$ toluene solution of TOAB $\left(7 \mathrm{~cm}^{3}\right)$ were mixed together and stirred vigorously for $30 \mathrm{~min}$. A freshly prepared $0.2 \mathrm{~mol} \mathrm{dm}^{-3}$ aqueous solution of $\mathrm{NaBH}_{4}\left(4 \mathrm{~cm}^{3}\right)$ was slowly added to the two-phase 
reaction mixture while stirring. Stirring was continued for $2 \mathrm{~h}$. After that, wine-red organic phase was separated and mixed with $0.24 \mathrm{mmol}$ of $\mathbf{2}, 3$ or 4 dissolved in $2 \mathrm{~cm}^{3}$ of toluene. The stirring was continued for about $1 \mathrm{~h}$. The solution was concentrated to $\approx 1 \mathrm{~cm}^{3}$ using a rotary evaporator, diluted with 100 $\mathrm{cm}^{3}$ of ethanol and left in a refrigerator for $24 \mathrm{~h}$. The functionalized AuNPs collected as a brownish black precipitate were again redispersed in ethanol and reprecipitated and this procedure was repeated for several times in order to remove any free compound still present in solid. AuNPs were also washed with acetone.

\section{Preparation of Self-assembled Layers}

Previously flame-annealed ${ }^{35} \mathrm{Au}(111) /$ mica substrates (Molecular Imaging Co.) were immersed in a $1 \mathrm{mmol}$ $\mathrm{dm}^{-3}$ solution of compound $\mathbf{1}$ in ethanol or compound $\mathbf{2}$ in a 1:1 mixture of ethanol and chloroform at room temperature for about $24 \mathrm{~h}$. After removing from solution, $\mathrm{Au}(111 / \mathrm{mica}$ substrates samples were rinsed with copious amount of solvent and dried in the stream of argon.

\section{Characterization of Self-assembled Layers on an Au(111) Surface}

Scanning Tunneling Microscopy (STM). The measurements were carried out in the constant-current mode under ambient conditions at room temperature using a home-built STM. $^{36}$ The STM tips were prepared by mechanically cutting a $\mathrm{Pt} / \mathrm{Ir}$ wire $(0.25 \mathrm{~mm}$ diameter $)$. Lateral STM distances were calibrated by precision of about $10 \%$. The obtained data were analyzed using the WSxM processing software. ${ }^{37}$

Atomic Force Microscopy (AFM). AFM imaging was performed using a Multimode Scanning Probe Microscope with Nanoscope IIIa controller (Veeco Instruments, Santa Barbara, CA) and a vertical engagement (JV) $125 \mu \mathrm{m}$ scanner. Measurements were done in air at ambient temperature and humidity of 50-60\%, using tapping mode with silicon tips (TESP, Veeco, nom. freq. $320 \mathrm{kHz}$, nom. spring constant of $42 \mathrm{~N} / \mathrm{m}$ ). The linear scanning rate was optimized between 1.0 and $1.5 \mathrm{~Hz}$ for the tapping mode and between 0.5 and $1.5 \mathrm{~Hz}$ with scan resolution of 512 samples per line. Processing and analysis of images were carried out using the NanoScope ${ }^{\mathrm{TM}}$ software (Digital Instruments, version V614r1) and WSxM processing software. $^{37}$

\section{Characterization of AuNPs}

FTIR spectroscopy. Transmission FTIR spectra of AuNPs were recorded at $4 \mathrm{~cm}^{-1}$ resolution at room temperature on a Bruker Equinox FTIR spectrometer.
The specimen was prepared as a $\mathrm{KBr}$ pellet of dry composite material.

$U V$-vis spectroscopy. UV-vis absorption measurements were carried out at room temperature on a Specord 200 spectrometer using a quartz cell at $2 \mathrm{~nm}$ resolution. The formation of AuNPs was confirmed via absorption of the plasmon band. Chloroform was used as a solvent for both free compounds 2, 3 and $\mathbf{4}$ and AuNPs capped by them.

Transmission electron microscopy (TEM). TEM images were obtained with a Zeiss microscope EM-10 operating at $80 \mathrm{kV}$. For microscopy the samples were suspended in chloroform and treated in the ultrasonic bath, then applied to the carbon-coated grid and dried in air. Analysis of core diameters was performed by ImageJ software.

\section{RESULTS AND DISCUSSION}

\section{Self-assembled Layers on an Au(111) Surface}

Nitrosoarene derivative 1. Figure 1a shows a large scale STM image of adlayer of compound $\mathbf{1}$ on an $\mathrm{Au}(111)$ surface. Typical Au terraces separated by monoatomic steps can be observed. Within the terraces, a large number of pitlike depressions are visible with the average diameter of 2-4 nm and a depth of approximately 0.25 $\mathrm{nm}$. This value is consistent with the expected height of an $\mathrm{Au}(111)$ single atomic step and according to literature these features can be assigned to gold vacancy islands whose formation is typical during the assembly process of thiols. $^{38,39}$

Figure $1 \mathrm{~b}$ shows a STM image recorded on a single terrace of the $\mathrm{Au}(111)$ substrate. Between a high number of $\mathrm{Au}$ vacancies (marked with arrow in Figure 1b), small domains of adsorbed molecules $\mathbf{1}$ are visible. In order to improve the quality of obtained molecular film and thus gain more insights into organization of molecules within the adlayer, we performed thermal annealing in solution. This procedure is expected to increase the domain size and decrease the density of vacancy islands. ${ }^{40}$ Following the usual room temperature assembly process, the molecular film was annealed in an ethanolic solution of compound $\mathbf{1}$ for $1 \mathrm{~h}$ at 78 ${ }^{\circ} \mathrm{C} .{ }^{41}$ By comparing morphology characteristics before (Figure 1b) and after an annealing step (Figure 1c), a decrease in a number of vacancy islands and an increase in domain size were observed which is consistent with the Ostwald ripening process. ${ }^{42}$ However, although domain size was increased we could not observe any long range molecular order within the adlayer of compound 1. Therefore, it seems that adsorption of molecules of monomeric nitrosoarene derivative $\mathbf{1}$ on an $\mathrm{Au}(111)$ leads to poorly organized monomolecular layer with molecules almost randomly distributed over the surface. 

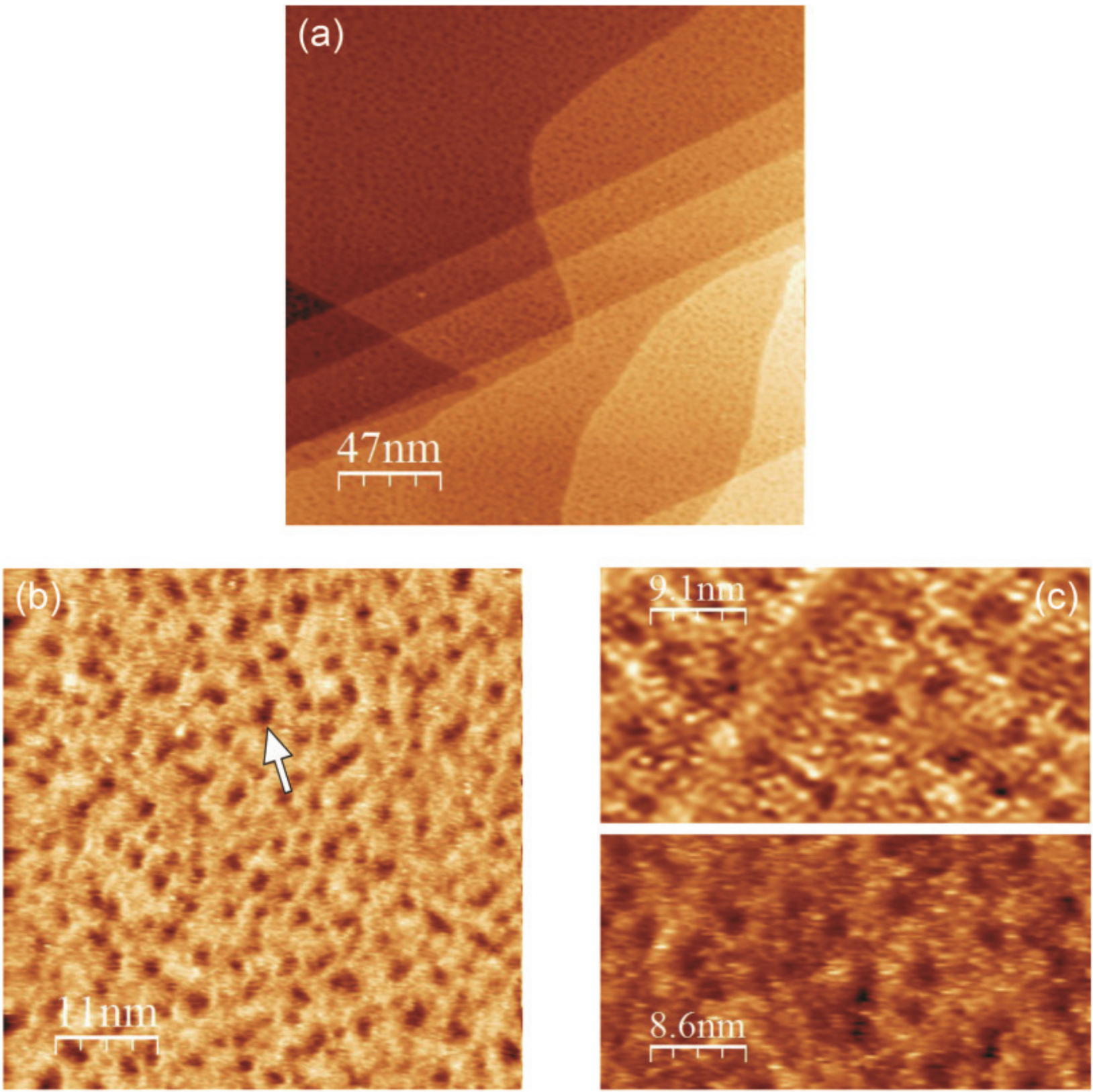

Figure 1. (a) $234 \mathrm{~nm} \times 234 \mathrm{~nm}$ and (b) $57 \mathrm{~nm} \times 57 \mathrm{~nm}$ large-scale STM images of adlayers of compound 1 on an Au(111) surface. The white arrow in (b) marks gold vacancy island. (c) STM images recorded on an adlayers of compound 1 after thermal annealing.

Nitrosoarene derivative 2. Figure 2a shows large-scale STM image of adlayer of compound 2 on an $\mathrm{Au}(111)$ surface from which good morphology of Au substrate characterized by the appearance of gold terraces separated by monoatomic steps is visible. Figure $2 \mathrm{~b}$, also representing a low-resolution STM image, point to periodical structure of the surface. High-resolution STM images such as one displayed in Figure $2 \mathrm{c}$ show that molecules of nitrosoarene derivative 2 form a wellordered SAM on an $\mathrm{Au}(111)$ surface. Detailed analysis of molecularly resolved images revealed that molecules are organized into a hexagonal structure at the intermolecular distances of $0.35 \pm 0.03 \mathrm{~nm}$. In addition, we could observe a hexagonal Moiré-type superstructure of $1.5 \mathrm{~nm}$ periodicity with a corrugation of $0.02 \mathrm{~nm}$. The appearance of long-range hexagonal Moiré-pattern within the monolayer of compound $\mathbf{2}$ is clearly visible from the corresponding autocorrelation image (inset in Figure 2c). Periodic modulation of molecular network could be assigned to a structural mismatch between the 

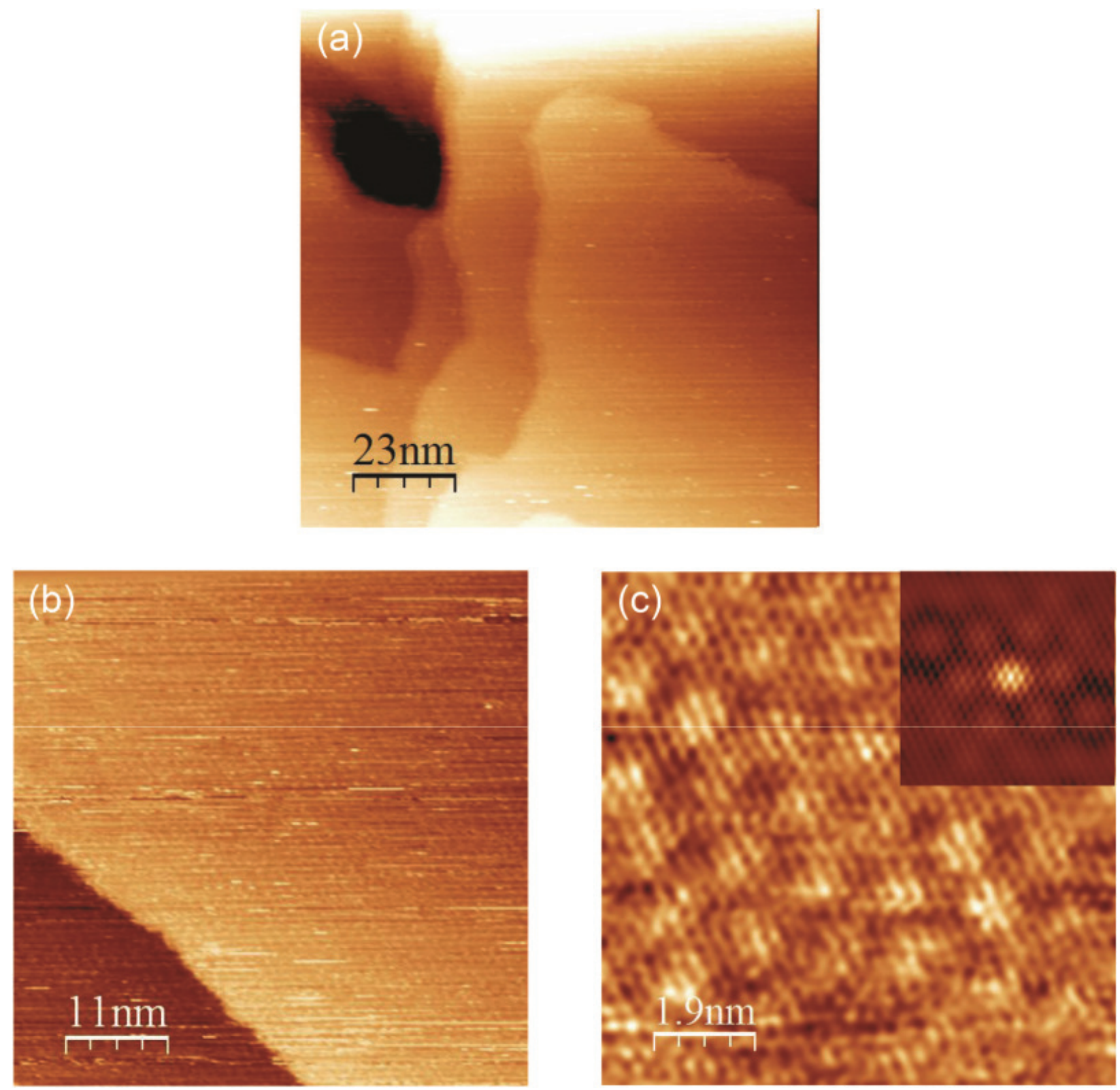

Figure 2. (a) $117 \mathrm{~nm} \times 117 \mathrm{~nm}$ and (b) $57 \mathrm{~nm} \times 57 \mathrm{~nm}$ large-scale STM images of adlayers of compound 2 on an Au(111) surface. (c) Fourier filtered high-resolution STM image $(9.5 \mathrm{~nm} \times 9.5 \mathrm{~nm})$ of SAM of 2 on an Au(111) surface. The inset represents the corresponding autocorrelation image of SAM of compound 2 showing long-range hexagonal Moiré-superstructure.

registry of molecules 2 and the underlying $\mathrm{Au}(111)$ lattice. Presumably, this could be induced by dominant intermolecular interactions of nitrosoarene residues within the molecular layer leading to occupation of different adsorption sites of the $\mathrm{Au}(111)$ lattice by $\mathrm{S}$ atoms. As it is known from the literature, the geometric height difference between various adsorption sites of sulfur atoms on an $\mathrm{Au}(111)$ lattice is about $0.02 \mathrm{~nm},{ }^{43}$ which is in good agreement with measured corrugation. The periodicity of the superstructure of $1.5 \mathrm{~nm}$ corre- sponds very well to $3 \sqrt{3}$ times that of the $\mathrm{Au}(111)$ lattice $(a=0.29 \mathrm{~nm})$ indicating a $3 \sqrt{3} \times 3 \sqrt{3}$ molecular arrangement, same as for SAMs of nitrosoarene derivatives studied in our recent paper. ${ }^{18}$ However, on contrary to the molecular adlayers of the recently studied compounds for which higher islands attributed to SABs were detected in the STM images, here we could not observe similar features.

To gain more insights into the surface topography of adlayer of compound 2 we have used AFM. Figure 3 


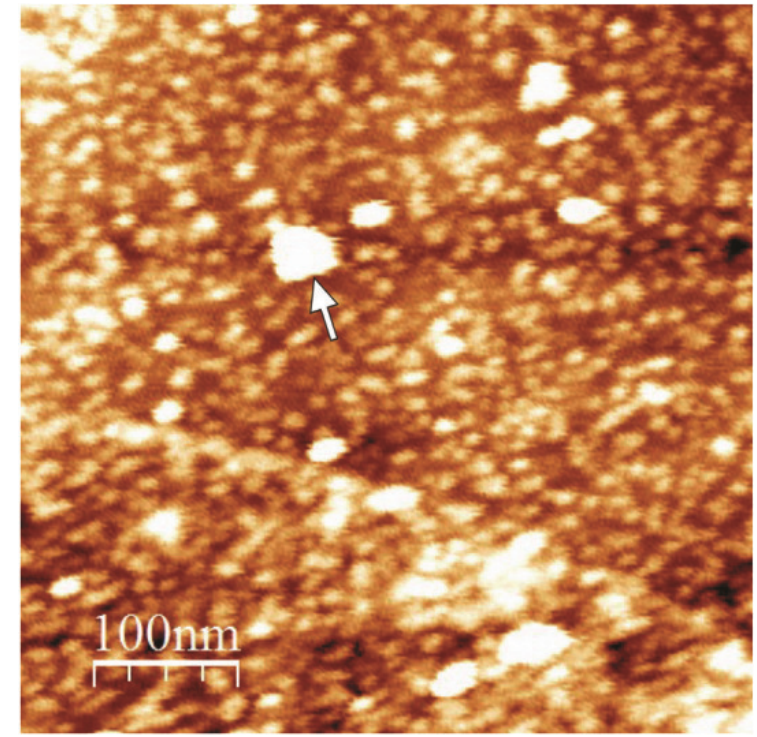

Figure 3. $500 \mathrm{~nm} \times 500 \mathrm{~nm}$ AFM image of adlayer of compound 2 on an $\operatorname{Au}(111)$ surface. Very bright spots on an $\mathrm{Au}(111)$ surface (such as one marked with white arrow) represent artifacts and were not included in height profile analysis.

shows an AFM height image of compound $\mathbf{2}$ adsorbed on an $\mathrm{Au}(111)$ surface from which numerous closepacked islands on the Au surface are visible. Notably, similar morphology of the surface was observed for adlayers of previously studied compounds. ${ }^{18}$ According to STM data, compound $\mathbf{2}$ forms only a well-ordered SAM with crystalline packing over extended areas. In regard to that, one would expect AFM images displaying uniform molecular layer covering $\mathrm{Au}(111)$ terraces. The appearance of islands, in fact, points to formation of bilayers and the height of these islands should represent the height difference between SABs and SAMs. Height profile analysis of the obtained AFM images revealed that the height of islands is approximately 1.5 $\mathrm{nm}$. Taking into account that molecules are tilted for approximately $30^{\circ}$ when adsorbed on an $\mathrm{Au}(111)$ surface, ${ }^{44}$ the measured value is in good agreement with the theoretical length of molecule 2 being $1.8 \mathrm{~nm}$, thus supporting formation of SABs. The inability to detect SABs regions by STM could be due the length of molecule 2 which is considerably longer in comparison to previously studied molecules. ${ }^{18}$ It is possible that during the STM imaging a tip is actually buried within a molecular layer in order to attain tunneling current. Examples of such invasive tip-sample interactions are familiar from the literature. ${ }^{45,46}$

Presented data indicate that the monomeric nitrosoarene derivative $\mathbf{1}$ is not able to form ordered SAM when adsorbed on an $\mathrm{Au}(111)$ surface. In addition, we could not observe any features corresponding to SABs regions. Thus results obtained imply that the

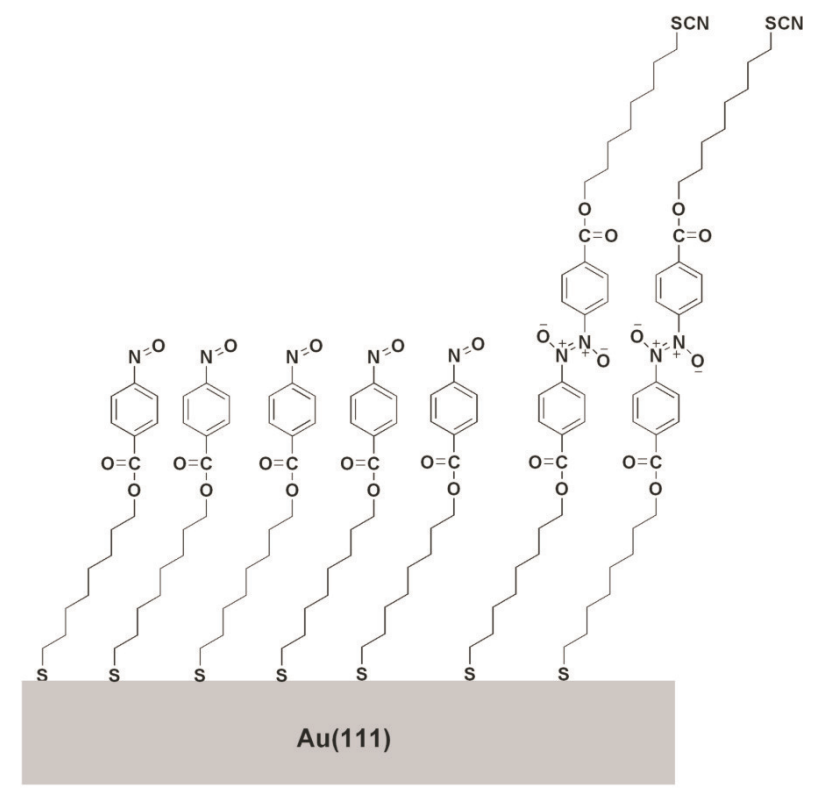

Figure 4. Schematic illustration of molecular adlayer of compound 2 on an $\mathrm{Au}(111)$ surface with the appearance of mono- (SAM) and bilayers (SAB).

electron-donating substituent in para-position prohibit dimerization of compound $\mathbf{1}$ also at the metal-solution interface (Scheme 2). On contrary, molecules of nitrosoarene derivative $\mathbf{2}$ self-assemble into wellordered SAM on an $\mathrm{Au}(111)$ surface displaying a $3 \sqrt{3} \times 3 \sqrt{3}$ structure. Moreover, results of AFM measurements indicate that they also tend to dimerize on an $\mathrm{Au}(111)$ surface by forming bilayers (Figure 4).

\section{Aggregation of AuNPs through (O)N=N(O) Bonds}

FTIR spectroscopy. Figures $5 \mathrm{a}$ and b show FTIR spectra of compounds $\mathbf{2}$ and $\mathbf{3}$ and of AuNPs capped by them. The major difference between the spectra of free molecules and those of AuNPs is the almost complete loss of intense SCN stretching vibration after adsorption of compounds $\mathbf{2}$ and $\mathbf{3}$ on the gold surface. This is a clear indication that nitrosoarene derivatives $\mathbf{2}$ and $\mathbf{3}$ are adsorbed on the surface of AuNPs through thiocyanate headgroup. Characteristic bands of nitrosoarenes can be observed for both AuNPs-2 and AuNPs-3 suggesting that nitrosoarenes are essential components of nanoparticles. As characterized by the appearance of the signal of asymmetric stretching vibration of the $(\mathrm{O}) \mathrm{N}=\mathrm{N}(\mathrm{O})$ bond at $1260 \mathrm{~cm}^{-1}$, compounds 2 and $\mathbf{3}$ are present in dimeric (azodioxide) form on the surface of AuNPs, just as are free compounds in solid state. There is no evidence for the presence of monomeric $\mathrm{N}=\mathrm{O}$ stretching vibration in the FTIR spectra of compounds $2 / 3$ nor AuNPs-2/AuNPs-3. Comparison with the FTIR spectra of AuNPs capped by compound 4 (Figure 5c), for which 

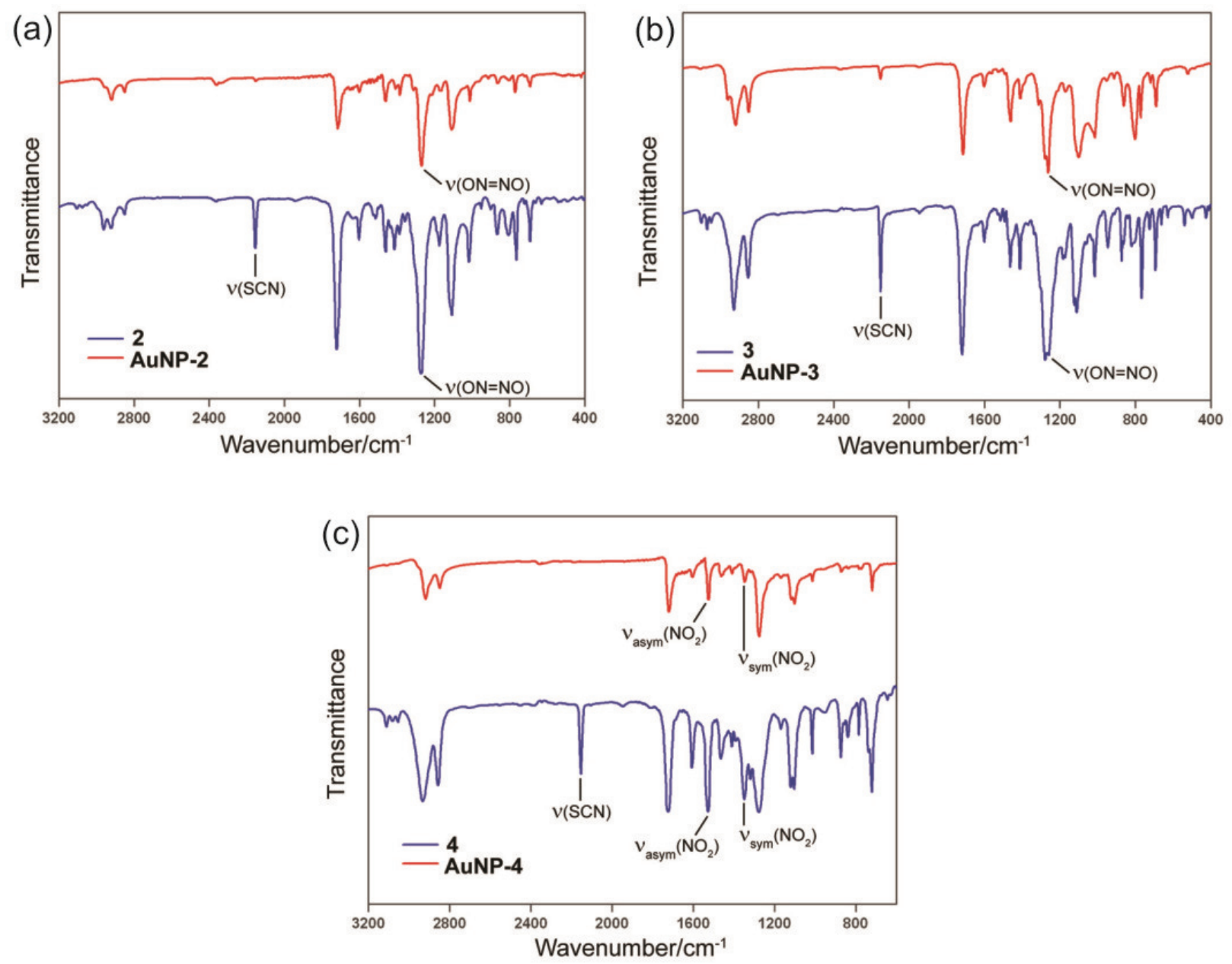

Figure 5. FTIR spectra of (a) compound 2 and AuNPs-2, (b) compound 3 and AuNPs-3 and (c) compound 4 and AuNPs-4. Spectra of free compounds 2-4 and AuNPs capped by them are depicted in blue and red colours, respectively.

the complete absence of SCN stretching vibration after adsorption on the surface of AuNPs was observed, suggests that very small signals of SCN stretching vibration in the spectra of AuNPs-2 and AuNPs-3 can be assigned to dimeric nitrosoarenes with free SCN termini. Nevertheless, the low intensity of these signals indicates that no appreciable quantity of these species is present on the AuNPs surface.

$U V$-vis spectroscopy. The dominant feature in the absorption spectrum of AuNPs is the presence of a surface plasmon (SP) absorption band in the visible region. SP band is a consequence of the collective oscillation of conduction band electrons induced by the interacting electromagnetic field. The position of SP band is very sensitive to the size, shape and interparticle spacing. ${ }^{4-49}$ In the UV-vis absorption spectra of free compounds $\mathbf{2}$ and $\mathbf{3}$ broad and weak absorptions with maximums at $770 \mathrm{~nm}$ can be observed (Figure 6a). These bands originate from the $n$ $\pi^{*}$ transition of monomeric form of nitrosoarenes that is dominant in solution at ambient temperature. The absorption spectra of AuNPs-2 and AuNPs-3 are practically identical and exhibit two peaks with maximums at $530 \mathrm{~nm}$ and $835 \mathrm{~nm}$ (Figure 6b). Since the position of the peak at $530 \mathrm{~nm}$ is consistent with the position of SP band in the spectrum of AuNPs stabilized by TOAB $\left(\lambda_{\max }=532 \mathrm{~nm}\right.$, Figure $\left.6 \mathrm{c}\right)$ it presumably corresponds to SP absorption band. The appearance of the second peak at $835 \mathrm{~nm}$ is not so straightforward. As described in the literature, the surface plasmon oscillation in AuNPs can be drastically altered if the individual nanoparticles come into close proximity so that they are electronically coupled to each other. ${ }^{49,50} \mathrm{Ag}$ gregation can lead to complicated absorption spectra with the additional red-shifted plasmon absorption. Resulting spectra usually contain the SP band due to single spherical AuNPs and the new peak due to interactions among individual nanoparticles. Since AuNPs capped by nitrosoarenes are able to form aggregates through interactions of exposed nitroso groups, the 

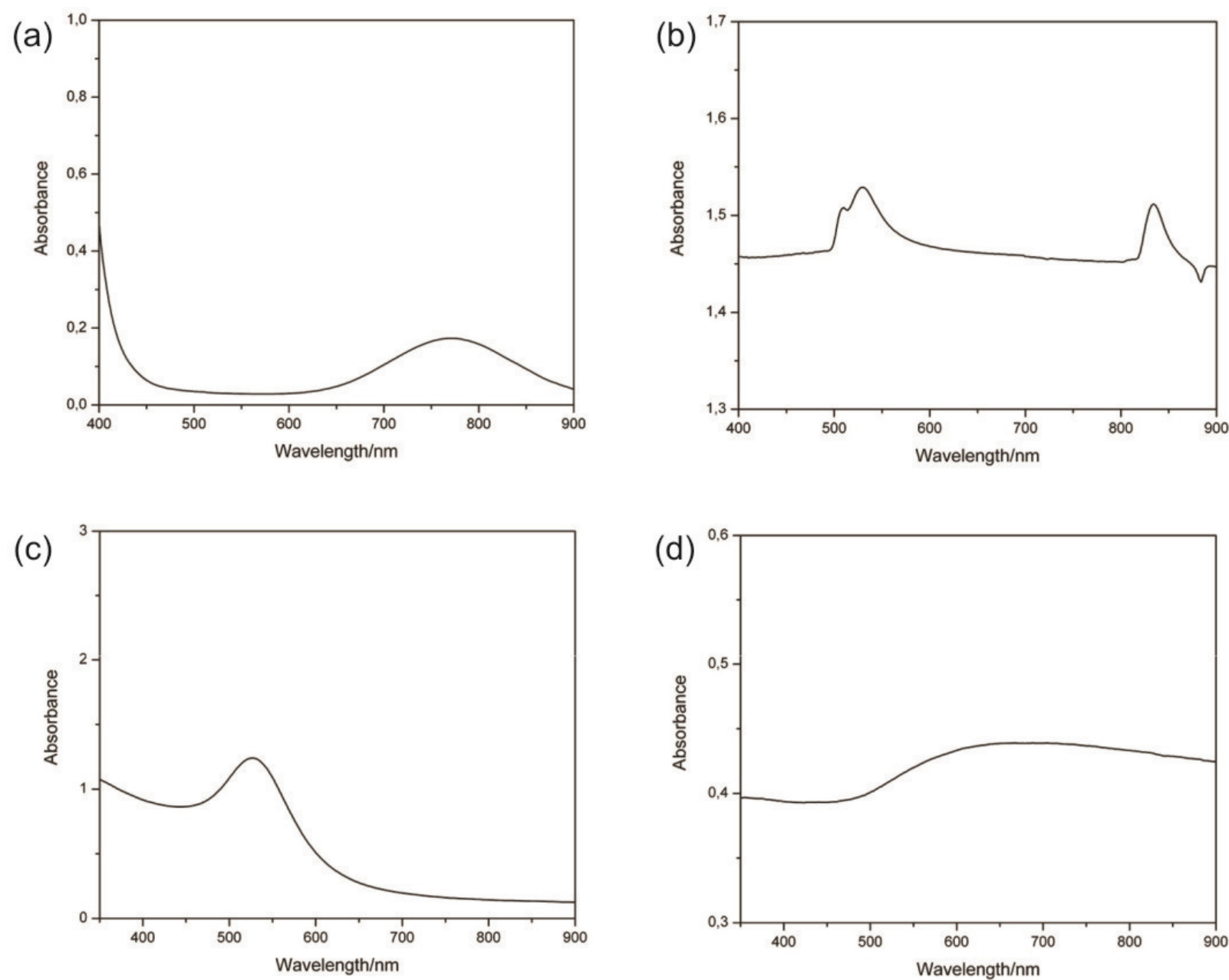

Figure 6. UV-vis spectra of (a) free compound 2, (b) AuNPs-2, (c) AuNPs-TOAB and (d) AuNPs-4. Due to the close similarity between the spectra of free compounds $\mathbf{2}$ and $\mathbf{3}$ and AuNPs-2 and AuNPs-3, only spectra of $\mathbf{2}$ and AuNPs-2 are shown. All spectra were recorded in chloroform.

peak at $835 \mathrm{~nm}$ was tentatively assigned to additional plasmon absorption band. Our assumption on aggregation of AuNPs-2 and AuNPs-3 is additionally supported by bluish color of their colloidal solutions in comparison to the red-wine colored solution of AuNPs capped by TOAB.

The broadening and the red shift of the SP band in the UV-vis spectrum of AuNPs-4 (Figure 6d) with respect to the SP band of AuNPs-TOAB (Figure 6c) indicates that irreversible agglomeration of AuNPs capped by nitroarene derivative had occurred.

Transmission Electron Microscopy (TEM). The size of AuNPs was examined by TEM. Figure 7a shows a TEM image and particle size distribution of AuNPs capped by compound 2. The AuNPs-2 display relatively wide distribution in size with the mean diameter of $5.6 \pm 2.1$ $\mathrm{nm}$. In addition to smaller spherical nanoparticles the appearance of some particle coalescence and formation of larger aggregates is visible. Similar features can also be observed in the TEM image of AuNPs capped by nitrosoarene derivative 3 (Figure $7 \mathrm{~b}$ ). The mean diameter of AuNPs-3 is $5.5 \pm 2.3 \mathrm{~nm}$ thus being comparable to the size of AuNPs-2. TEM data for both AuNPs-2 and AuNPs-3 are in agreement with the results of UVvis spectroscopy that also pointed to aggregation of AuNPs.

Morphology of AuNPs capped by nitroarene derivative 4 differs substantially in comparison to AuNPs capped by nitrosoarene derivatives $\mathbf{2}$ and $\mathbf{3}$. AuNPs-4 form large agglomerates as evidenced by TEM image shown in Figure 8. Irreversible agglomeration of AuNPs-4 was already indicated by UV-vis spectroscopy data. However, on the basis of the lengths of molecules $\mathbf{2}$ and $\mathbf{4}$ one would expect them to display similar properties i.e. to be equally effective in stabilizing AuNPs from agglomeration.

Due to the high curvature of a colloidal gold surface, the chain termini of the organic molecules acting 
(a)

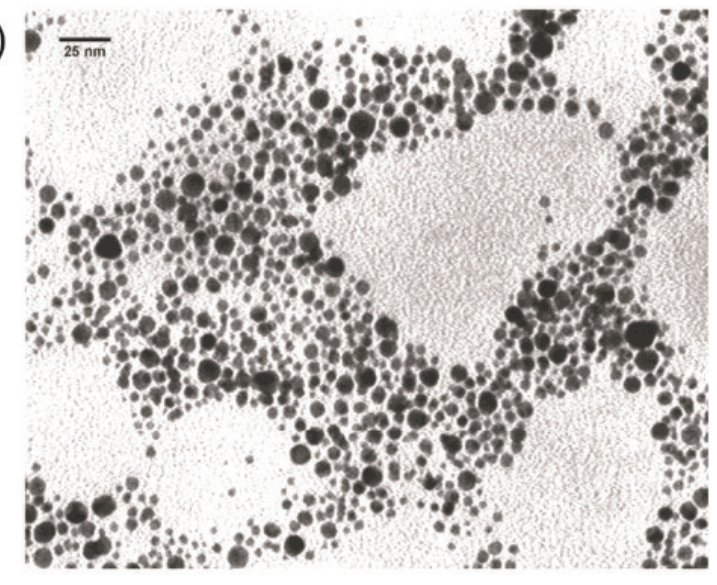

(b)

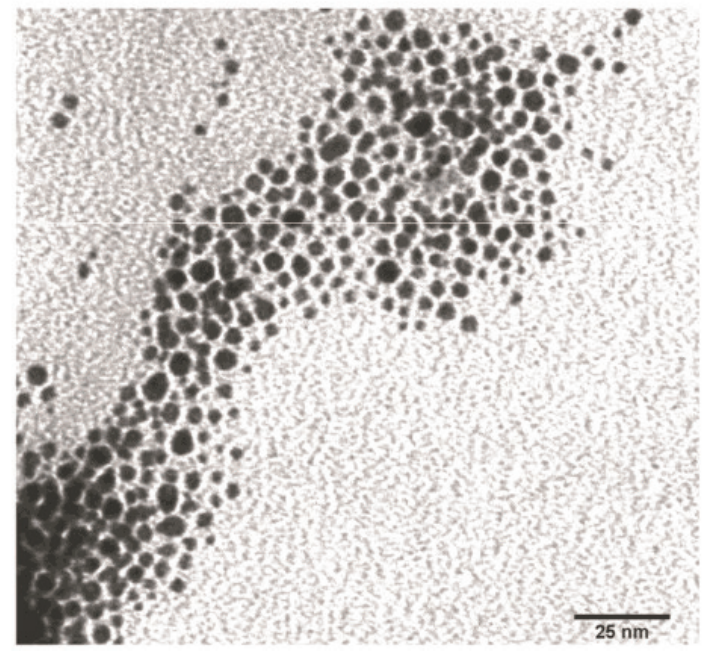

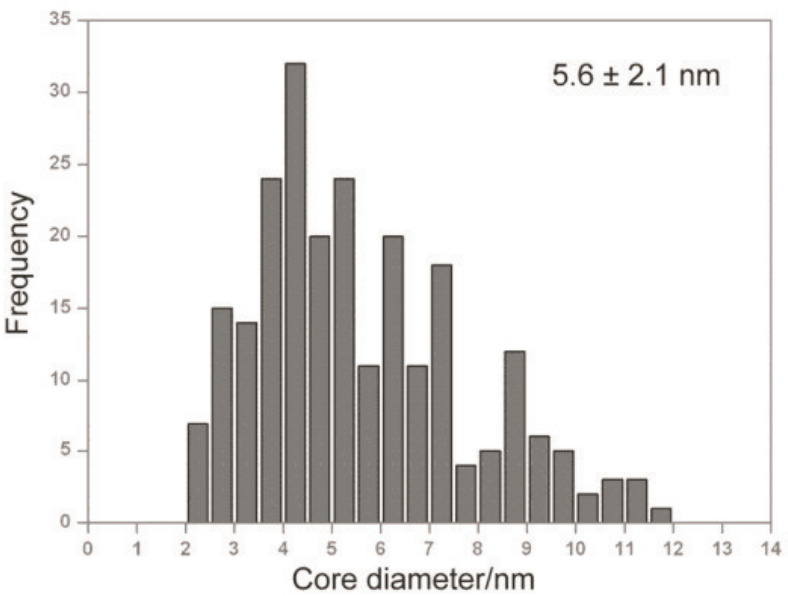

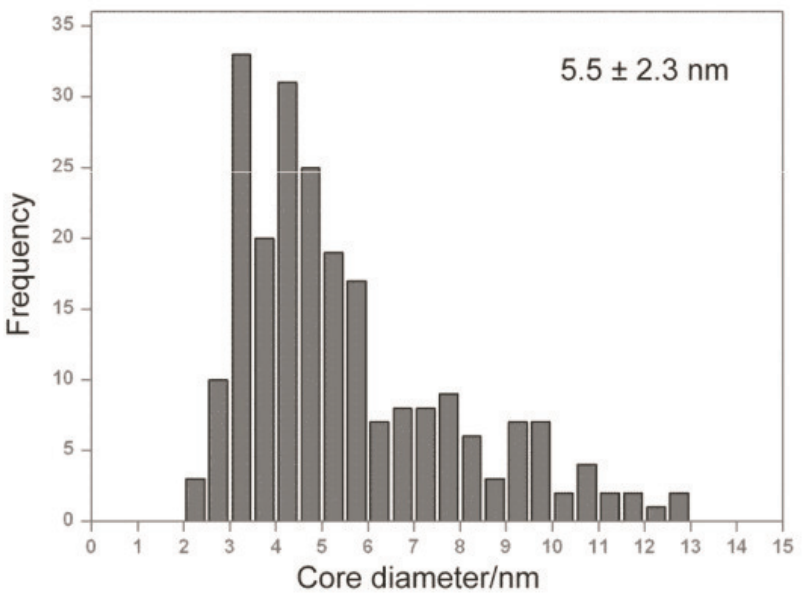

Figure 7. TEM images and corresponding histograms of size distributions for (a) AuNPs-2 and (b) AuNPs-3.

as stabilizing agents are more diverged than the head groups. The molecules are more ordered near the surface and become disordered and more mobile moving away from the surface. This causes interpenetration of the adjacent alkyl chain termini into this gap and the Van der Waals forces make the structure more ordered and stable. In the case of nitrosoarene-terminated nanoparticles, what is most probable to occur is that when they are brought in proximity they form azodioxide bonds (Figure 9), which act together with the Van der Waals forces to stabilize nanoparticles. Strong support of interconnection of AuNPs capped by nitrosoarene derivatives $\mathbf{2}$ and $\mathbf{3}$ arises from their FTIR spectra which show that nitrosoarenes are present in dimeric form on gold surface. Significantly, there is no appreciable quantity of dimeric nitrosoarenes with free SCN termini as evidenced by an almost complete absence of the signal of SCN stretching vibration. The small quantity of these species is expected to be present because it is not geo-

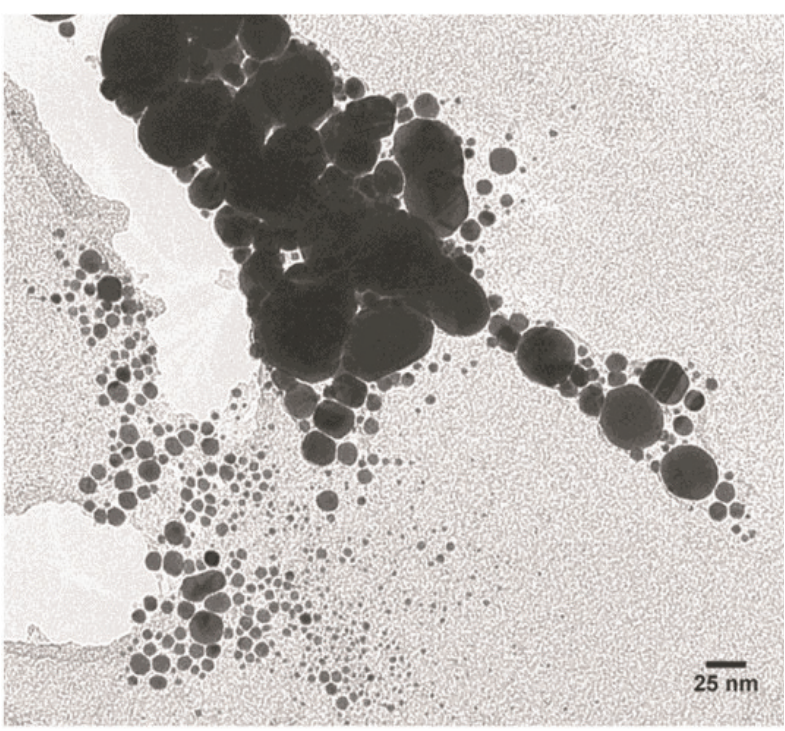

Figure 8. TEM image of AuNPs-4. 
<smiles>CCSCCCCCCCCOC(=O)c1ccc([N+]([O-])=[N+]([O-])c2ccc(C(=O)OCCCCCCCCSCC)cc2)cc1</smiles>

Figure 9. Schematic illustration of possible linkage of AuNPs capped by compound 2 via $(O) N=N(O)$ bonds.

metrically possible for groups on two roughly spherical surfaces to entirely bond together and consume one another. In addition, we cannot preclude that some of the azodioxide couplings are intra-nanoparticle, that is, laterally on the surfaces of individual nanoparticles. But due to the already discussed curvature of the colloidal surface and enhanced mobility of the terminal groups, this might occur only to a minor extent. In the case of an analogous system of nanoparticles stabilized by nitroarene-terminated molecules, there is no possibility of formation of azodioxide bonds and the metal-metal agglomeration occurs.

\section{CONCLUSIONS}

We have investigated dimerization of two nitrosoarene derivatives, of which one appears as monomer and the other as dimer, on an $\mathrm{Au}(111)$ surface using STM and AFM. STM images revealed that dimeric nitrosoarene derivative forms well-ordered SAM with molecules arranged into hexagonal $3 \sqrt{3} \times 3 \sqrt{3}$ structure. AFM measurements indicated that this compound also forms bilayers (SABs) on an $\mathrm{Au}(111)$ surface. Adsorption of monomeric nitrosoarene derivative resulted only in poorly ordered monolayer thus demonstrating the influence of structural factors on dimerization at metalsolution interface.

In the second part of this work we studied the ability of C-nitrosoarenes to dimerize on the 3D surface of AuNPs and induce aggregation of AuNPs through azodioxide $(\mathrm{O}) \mathrm{N}=\mathrm{N}(\mathrm{O})$ bonds. As revealed by FTIR spectroscopy, nitrosoarene derivatives are present as dimers on the surface of AuNPs with only minor proportion of species containing free thiocyanate termini. UV-vis spectroscopy and TEM data supported aggregation of AuNPs that is most likely induced by interparticle interaction of exposed nitroso groups. In the case of AuNPs capped by nitroarene-terminated molecules, in which the interlinking of particles was prevented by introduced nitro functionality, irreversible agglomeration was observed.

Acknowledgements. We gratefully acknowledge the financial support to this work from the Ministry of Science, Education, and Sports of the Republic of Croatia, No. 119-1191342-1334, 035-0352828-2840, and 098-0982934-2744. In addition, we thank Dr. Sc. Andreja Gajović (Ruđer Bošković Institute) and Dr. Sc. Srećko Gajović (Croatian Institute for Brain Research) for TEM measurements.

\section{REFERENCES}

1. H. Vančik, Aromatic C-nitroso Compounds, Springer, Dordrecht, 2013.

2. D. A. Fletcher, B. G. Gowenlock, and K. G. Orrell, J. Chem. Soc. Perin Trans 2 (1998) 797.

3. D. A. Fletcher, B. G. Gowenlock, K. G. Orrell, and V. Sik, Magn. Reson. Chem. 33 (1995) 561.

4. D. A. Fletcher, B. G. Gowenlock, K. G. Orrell, V. Sik, D. E. Hibbs, M. B. Hursthouse, and A. K. M. Malik, J. Chem. Soc. Perin Trans 2 (1996) 191.

5. B. G. Gowenlock and W. Lütke, Quart. Rev. 12 (1958) 321

6. F. D. Greene and K. E. Gilbert, J. Org. Chem. 40 (1975) 1409.

7. M. L. Greer, H. Sarker, M. E. Medicino, and S. C. Blackstock, J. Am. Chem. Soc. 117 (1995) 10460.

8. K. G. Orrell, V. Sik, and D. Stephenson, Magn. Reson. Chem. 25 (1987) 1007.

9. K. G. Orrell, D. Stephenson, and T. Rault, Magn. Reson. Chem. 27 (1989) 368.

10. J. P. Snyder, M. H. Heyman, and E. Suciu, J. Org. Chem. 40 
(1975) 1395

11. T. A. J. Wajer and T. J. De Boer, Recueil 91 (1972) 565.

12. M. Azoulay and E. Fischer, J. Chem. Soc. Perkin Trans 2 (1982) 637.

13. D. A. Fletcher, B. G. Gowenlock, and K. G. Orrell, J. Chem. Soc. Perkin Trans 2 (1997) 2201.

14. B. G. Gowenlock and G. B. Richter-Addo, Chem. Soc. Rev. 34 (2005) 797.

15. I. Halasz, E. Meštrović, H. Čičak, Z. Mihalić, and H. Vančik, J. Org. Chem. 70 (2005) 8461.

16. H. Vančik, V. Šimunić-Mežnarić, E. Meštrović, S. Milovac, K. Majerski, and J. Veljković, J. Phys. Chem. B 106 (2002) 1576.

17. R. Glaser, R. K. Murmann, and Ch. L. Barnes, J. Org. Chem. 61 (1996) 1047

18. I. Biljan, M. Kralj, T. Mišić Radić, V. Svetličić, and H. Vančik, J. Phys. Chem. C 115 (2011) 20267.

19. H. B. Akkerman, P. W. M. Blom, D. M. de Leeuw, and B. de Boer, Nature 441 (2006) 69.

20. N. Fishelson, I. Shkrob, O. Lev, J. Grun, and A. D. Modestov, Langmuir 17 (2) (2001) 403.

21. W. Huang, G. Masuda, S. Maeda, H. Tanaka, and T. Ogawa, Chem.-Eur. J. 12 (2005) 607.

22. R. L. McCreery, Chem. Mater. 16 (23) (2004) 4477.

23. M. A. Reed, C. Zhou, C. J. Muller, T. P. Burgin, and J. M. Tour, Science 278 (1997) 252.

24. I. Biljan, G. Cvjetojević, V. Smrečki, P. Novak, G. Mali, J. Plavec, D. Babić, Z. Mihalić, and H. Vančik, J. Mol. Struct. 979 (2010) 22.

25. B. G. Gowenlock, M. J. Maidment, K. G. Orrell, I. Prokeš, and J. R. Roberts, J. Chem. Soc. Perin Trans 2 (2001) 1904.

26. H. J. Talberg, Acta Chem. Scand. Ser. A 33 (1979) 289.

27. J. W. Ciszek, M. P. Stewart, and J. M. Tour, J. Am. Chem. Soc. 126 (2004) 13172.

28. J. W. Ciszek, M. P. Stewart, and J. M. Tour, Chem. Mater. 17 (2005) 5684

29. K. G. Orrell, D. Stephenson, and J. H. Velarque, J. Chem. Soc. Perkin Trans 2 (1990) 1297.

30. G. Pace, V. Ferri, C. Grave, M. Elbing, C. Hänisch, M. Zharnikov, M. Mayor, M. A. Rampi, and P. Samori, PNAS 104
(2007) 9937.

31. H. Wolf, R. Ringsdorf, E. Delamarche, T. Takami, H. Kang, B. MIchel, C. Gerber, M. Jaschke, H.-J. Butt, and E. Bamberg, J. Phys. Chem. 99 (1995) 7102.

32. M. Brust, J. Fink, D. Bethell, D. J. Schiffrin, and C. J. Kiely, J. Chem. Soc. Chem. Commun. (1995) 1655.

33. M. Brust, M. Walker, D. Bethell, D. J. Schiffrin, and R. Whyman, J. Chem. Soc. Chem. Commun. (1994) 801.

34. A. Manna, P. Chen, H. Akiyama, T. Wei, K. Tamada, and W. Knoll, Chem. Mater. 15 (2003) 20.

35. M. H. Dishner, M. M. Ivey, S. Gorer, J. C. Hemminger, and F. J. Feher, J. Vac. Sci. Technol. A (1998) 3295.

36. M. Wilms, M. Schmidt, G. Bermes, and K. Wandelt, Rev. Sci. Instrum. 69 (1998) 2696.

37. I. Horcas, R. Fernández, J. M. Gómez-Rodríguez, J. Colchero, J. Gómez-Herrero, and A. M. Baro, Rev. Sci. Instrum. 78 (2007) 013705.

38. G. E. Poirier, Langmuir 13 (1997) 2019.

39. G. Yang andG. Liu, J. Phys. Chem. B 107 (2003) 8746.

40. E. Delamarche, B. Michael, H. Kang, and C. Gerber, Langmuir 10 (1994) 4103.

41. L. A. Bumm, J. J. Arnold, L. F. Charles, T. D. Dunbar, D. L. Allara, and P. S. Weiss, J. Am. Chem. Soc. 121 (1999) 8017.

42. O. Cavalleri, A. Hirstein, and K. Kern, Surf. Sci. 340 (1995) L960.

43. H. Kondoh, M. Iwasaki, T. Shimada, K. Amemiya, T. Yokoyama, T. Ohta, M. Shimomura, and S. Kono, Phys. Rev. Lett. 90 (2003) 066102.

44. J. C. Love, L. A. Estroff, J. K. Kriebel, R. G. Nuzzo, and G. M. Whitesides, Chem. Rev. 105 (2005) 1103.

45. S. N. Magonov and M. H. Whangbo, Surface Analysis with STM and $A F M, \mathrm{VCH}$, Weinheim, 1996.

46. B. Zhang and E. Wang, J. Chem. Soc. Faraday Trans. 93 (2) (1997) 327.

47. M. A. El Sayed, Acc. Chem. Res. 34 (2001) 257.

48. C. L. Haynes and R. P. Van Duyne, J. Phys. Chem. B 105 (2001) 5599.

49. S. Link and M. A. El Sayed, J. Phys. Chem. B 103 (1999) 8410.

50. S. K. Ghosh and T. Pal, Chem. Rev. 107 (2007) 4797. 